\title{
POSITIONING ONLINE LEARNING AS A STRATEGIC ASSET IN THE THINKING OF UNIVERSITY PRESIDENTS AND CHANCELLORS
}

\author{
Samuel H. "Pete" Smith \\ Assistant Vice President, Academic Affairs \\ University of Texas, Arlington \\ Samuel H. Smith \\ President Emeritus \\ Washington State University
}

Robert Samors

Associate Vice President

National Association of State Universities and Land Grant Colleges

A. Frank Mayadas

Program Director

Alfred P. Sloan Foundation

\section{INTRODUCTION}

Within our nation's public universities, online courses and programs have been increasing in number. This increase has led to the establishment of a National Commission on Online Learning through a collaborative effort between the Alfred P. Sloan Foundation and the National Association of State Universities and Land Grant Colleges. This commission intends to examine the core questions: how do college and university presidents and chancellors view online learning, what levels of information-both operational and policy-related-do they have about this developing field, and do they view it as a strategic asset or simply a newer means of teaching students?

Online learning is becoming an increasingly popular way for students to take courses and for faculty to teach, with the number of students taking at least one online course growing more than ten times as rapidly as the head count enrollments in post-secondary education. Clearly, the time is right to reframe a national dialogue amongst the leaders of our traditional universities and colleges about this asset.

Many of the earlier dialogues amongst presidents and chancellors relative to online learning focused on the quantity and, to a lesser extent, the quality of online instruction and its promised impact on our traditional campuses. Previously, online learning was also often associated with for-profit universities which to date remain in a growth phase and are developing academic acceptance.

Several questions emerged early in our research planning: 
- Can we discern from conversations with presidents and chancellors, how they believe their institutions are benefiting from their online learning programs?

- Do they view online education specifically as a strategic asset for their institution?

- In what ways do they envision this asset developing in the future?

- What impediments do they face in nurturing and supporting this development?

- What ideas, information, or strategies would allow presidents and chancellors to promote this development?

\section{METHODS}

At the heart of this study was a series of interviews with university leaders on the topics of online learning and their strategic thinking relative to this learning format. The preferred method of establishing the interviews was to contact initially either the president or the administrator responsible for that institution's online learning program to arrange a structured interview.

Early on, it was found to be most helpful if one or two of the administrators responsible for the online learning programs could be interviewed first to gain a baseline understanding of what they had accomplished and the institution's future goals. With that information in-hand, the presidents themselves were then interviewed.

In total, twelve research interviews were conducted. In the selection of institutions to be included in this study we attempted to include a range of historical and operational involvement in distributed learning. We initially concentrated on comparatively large, public universities or systems, including statewide systems, that are relatively new to offering online degree programs, as well as those which historically have been leaders in this developing field. We also selected traditional multi-campus universities with a strong research-intensive central campus (with and without a medical school) and universities that are developing or reinvigorating branch campuses or campuses where the primary emphasis is on teaching and not research.

In order to obtain a geographically diverse sampling, interviews were carried out with school leaders in the following states: Florida, Illinois, Maryland, Massachusetts, New York, Pennsylvania, Texas and Washington.

\section{INITIAL INTERVIEW RUBRIC}

During our initial interviews, it became clear that we needed to provide a framework for discussion, tacitly listing a number of areas at the institution that might be affected by online learning initiatives, thus leading the university leader to a more detailed discussion of online learning as a strategic asset. Initially we isolated a number of policy areas which presidents might readily identify as being impacted by online learning:

Recruitment/Access_-Online learning systems are being used at the institution to increase student access and increase enrollment in individual for credit or not for-credit courses, certificates or degree programs. Student recruitment is clearly affected by the presence of online learning classes and programs and the institution's ability to provide blended on-campus and online classes. 
Retention-The availability of online programs and technologies not limited by traditional calendars or geographies provides students with increased flexibility to gain desired coursework or mentoring.

Enrollment Management-Online learning is being used to enhance enrollment of specific student categories or manage enrollment on or between individual campuses.

Degree Completion-Beyond retention, online learning is being used to enable late-degree students to complete their degree requirements (for example, an international student who faces visa challenges late in their study career and completes degree work abroad).

Responsive Program Development-Online learning programs can often be more quickly initiated than traditional to meet a specific need or serve a particular student population.

Disaster Preparedness - Online learning systems play a role in the campus or system business continuity plan, enabling students to continue their degree programs during periods when their institution is limited in operations or closed.

Effects on Traditional Classrooms-Online learning has created increased expectations for on-campus technology and technology-based interactions including faculty and students.

Blended Courses and Programs-Online learning is being used to attract students to campuses when full time, traditional on-site enrollment is either not possible or not desirable.

Continuing and Professional Education and Certification-Online learning is being used very effectively in the delivery of continuing education or professional development required for certification.

Quality of Instruction-Online learning has increased awareness, fostered discussions and promoted strategies to enhance the quality of instruction both online and in the traditional classroom.

Cost of Instruction-Online learning has increased awareness, fostered discussions and promoted strategies about cost of instruction at the institution.

Technology Infrastructure-Online learning has not only created an expectation that the institution's technology infrastructure will be constantly upgraded, but provides additional incentive for infrastructure development which benefits all areas of the institution's operations.

Physical Plant/Capacity Balancing-Online delivery has allowed institutions to serve more students while providing for more effective utilization of classrooms, physical facilities, faculty and staff.

Faculty Development and Incentives-Online teaching opportunities are considered to have positively impacted the recruitment and retention of digitally creative faculty and staff. It has also given institutions a viable means of actually helping to develop employees' capabilities and provide realistic incentives.

Partnerships-Online learning programs have created or been central to new partnerships with other institutions or organizations nationally or internationally. 
Political Outreach-Online learning has given the institution increased visibility in legislative settings and the ability to provide service to varied constituents in any political district or area.

Alumni and Donor Outreach-Online learning enables institutions to continue to serve their graduates educationally, thus enhancing alumni and development relationships and activities.

This rubric was in no way intended to represent a complete list of potential benefits to the institutions, but rather to begin discussions in the interview format, with expectations that new areas of benefit would emerge within each discussion.

At the same time, this developing list of topics does represent a solid framework for discussions, and might also serve as an outline of talking points as this national dialogue with university leaders unfolds. Clearly, this set of topics allowed the interviewees to view online education in a broader, more comprehensive way than simply through the lens of enrollment.

We intentionally did not make use of the Sloan-C "five quality pillars"-access, learning effectiveness, faculty satisfaction, cost-effectiveness and overall student satisfaction-in large part because this very logical and useful organizational system appeared to be developed primarily by individuals involved in the operations of online learning, and we wanted to determine if the same concepts would emerge from the presidents.

\section{RESULTS OF QUALITATIVE INTERVIEWS}

Our initial interviews revealed a general pattern of executive thought that is emerging, particularly for presidents at our larger public universities or university systems.

First, interviews with higher education presidents quickly emphasized the importance of an internal champion for distributed education at the institution, often a middle- to upper-middle level central administrator or faculty visionary. These individuals and their many faculty colleagues have typically developed an evolving approach to delivering higher education that is dramatically changing, and are critical to the understandings expressed by the school or system's CEO, whose own professional experience usually reflects more traditional approaches to teaching and learning. In their enthusiasm, these champion supporters continue to educate their university's leadership on the growth and broad potential of online learning.

Discussions and early attempts at educating presidents often centered at first on demonstrating the potential of online education to impact enrollment and the learning experiences of students already enrolled in online courses. It is important nonetheless to urge caution when encouraging university leaders to view online learning simply and solely as a means to increase their enrollment. Online learning may provide increased enrollment, but depending on the individual institution's business model, this may be of only limited strategic value. Depending on the individual institution, on a state by state basis there is a wide range of models that determine levels of financial support. Some institutions are compensated on the basis of student numbers, many are not. In most cases, if state funding is based on student numbers there is a limit on either the level or amount of compensation.

Among the presidents, there is also a reasonably clear understanding that enrollment in online courses is growing and is becoming a recognizable portion of the reported numbers of students enrolled in our major 
universities.

If we are to convince presidents of the value of online learning, we must be careful not to make claims that cannot be substantiated. Presidents remain cognizant that $80-90 \%$ of their students are still taking courses in the traditional manner. They approach all counts and statistics with a finely trained eye, and a healthy skepticism for numbers that might not be making rational comparisons. Conversations frequently included a desire for more accurate numbers of online learners that take into account those who were "truly online" versus those in "blended" or "technology enhanced” learning situations.

One persistent interview theme was the danger of over-selling online learning based on enthusiasm and various methods of counting online learning students. Presidents and chancellors clearly remember the early rhetoric of a decade ago that online learning enrollments were going to grow at exaggerated rates and that for-profit universities would dominate the market.

In nearly every interview, it became immediately apparent that any dialogue about online learning requires a consistent vocabulary or common terminology. Interviews with campus administrators or individuals not involved in online learning are hampered by discussions on the meaning of descriptors. Online learning was frequently confused during the interviews with distance education, technology enhanced learning, blended courses, interactive learning, hybrid programs and a dozen other terms. Labels such as "asynchronous learning networks (ALN) brought nothing but confusion.

When asked about the president's perception of the quality and the role online learning plays in quality issues, there is still a widespread perception that it is a learning environment probably below the quality of traditional on-site, face to face instruction. Logically, when pressed, interviewees did routinely admit that one could only hope that there would be as much evaluation of on-site teaching as there has been of online teaching. The discussions would usually evolve to recognition that there is a range of educational quality in both on-site and online courses.

Interviewees also consistently noted lack of clear data and comparisons of the costs of online versus face to face instruction. Any national dialogue about online learning as a strategic asset will require clearer, more detailed information and analysis in this regard for the decision-makers. Simply put presidents want to know the costs of online learning and how they compare to what they are already paying for face-toface instruction.

In the views of university system heads interviewed, there are clear distinctions relative to the type of campus and the current applicability of online learning to that campus. When a campus is perceived as research oriented, as is often the case with the central or main campus, there is much less CEO-expressed interest in online learning as compared to campuses which boast a stronger teaching mission.

This is not unsurprising, but complicates how the President views online learning. On a research-intensive campus, given a choice of what to fund, a research area that can generate external funds and prestige will probably take precedence over online learning.

It is also important to remember that the primary office of the president is most commonly on the research-based main campus and thus provides the most intensive, daily contact with those primarily interested in research, grants and contracts. An interesting footnote, though, is that campuses with a medical school often do have a significant online presence, primarily for the purpose of certification and 
continuing professional education.

In a technological sense, when pressed, respondents noted that online education had an effect not only on classroom instruction but also the technical infrastructure to support institution-wide information technology (IT). Respondents though did not immediately highlight this aspect without discussion and prompts. Only one of the interviewees is nationally recognized for his personal use of IT tools and technologies, and not surprisingly, none of the other respondents spontaneously described themselves as being exceptionally proficient with the latest technology.

It is significant to note that, commonly with the university system heads interviewed, one or more campuses in particular was/were identified as being at the center of their efforts in online learning. The campus identified as having the greatest online enrollment was usually not the main campus although the individual responsible for system wide online programs was typically located at the main campus.

For most interviewees, the concept of "truly distant" learners was less common, a conceptualization that differs significantly from the profiles of online learners often heard from professionals in the field. The concept of localness - a vision of online learners located close to a campus - seems to hold true but is not recognized across the board. This is obvious particularly with campuses where a significant number of courses or degree programs are blended in nature. In that same light, if there was one particular surprise uncovered in these interviews, it was the consistent lack of significant interest in expanding online learning into the international market. When it was reiterated in these interviews that anyone, anywhere can take the online learning courses or degree programs, the discussants' focus remained on specific state, regional or national markets or needs.

Also noticeably absent were spontaneous responses highlighting the value of online learning to influence alumni and donor relations, partnerships, or political outreach.

\section{STRATEGIC ASSET OR OPERATIONAL NECESSITY?}

As the interviews progressed, the notion of "strategic asset" itself developed in the thinking of the authors, potentially providing a summary point on the thinking of the interviewed presidents relative to online learning. In sum, did the university CEOs interviewed see online learning as a strategic asset, or simply another operational component of their educational operations in the current day and age?

From a definition standpoint, strategic assets are those that have a planned, direct and significant impact on achieving objectives and strategic plans across the institution. How prepared are presidents and strategic planners at colleges and universities to recognize the strategic importance of online or distributed learning?

In addition to the themes outlined above, selected interviewees were specifically asked to highlight locations within their institution's own strategic plan which outlined online learning and its importance to the school or system. Responses to this interview prompt varied, with online learning oftentimes not readily identifiable within the institution's publicly available strategic vision document.

After reviewing the collected interview data from this project, we can clearly state that the broadest impact that online learning might bring to an institution has not crystallized conceptually for strategy leaders in college and university settings. Although the presidents who spoke with us were often familiar 
with or had been briefed on developing online learning trends and their operational importance, we perceived a clear need for the positioning of online education as a strategic asset, rather than simply "another way of doing business" in the 21st Century, an asset that brings positive influence in a systemic way to multiple facets of the modern-day university. It was hoped that the baseline nature of leadership thought uncovered in this interview-based research might serve as a catalyst for a future study, as well as spur a national dialogue about online learning and its strategic positioning

\section{NASULGC INITIATIVES AND QUANTITATIVE RESEARCH}

Following the completion of the qualitative study, conversations to expand this research and executivelevel dialogue began with Drs. Peter McPherson, President, and Mortimer Neufville, Executive Vice President, of the National Association of State Universities and Land-Grant Colleges (NASULGC). NASULGC is the oldest and largest association of public universities and has a history of successfully stimulating and conducting national dialogues on emerging issues of importance in American higher education.

In May 2007, the National Association of State Universities and Land-Grant Colleges (NASULGC, A Public University Association), in cooperation with the Alfred P. Sloan Foundation, appointed the NASULGC-Sloan National Commission on Online Learning. Under the direction of Robert Samors, Associate Vice President, NASULGC, and with the research support of Jeff Seaman, Chief Information Officer and Survey Director, Sloan-C, this survey initiative was designed to gage in greater detail CEO views on distributed learning as truly systemic, reaching across the modern university [1].

Survey data previously collected by the Sloan Foundation [2, 3] clearly showed that online learning continues to emerge in the mainstream of higher education in both size and breadth of course and program offerings. In particular, previous Sloan-supported surveys solicited views from the academic community as well as from chief academic officers relative to online education.

What remained unquantified, however, was an answer to one of Frank Mayadas' initial questions and that was how to better understand the views and experiences of presidents and chancellors relative to online learning, and specifically to explore the role of online learning in their strategic thinking, in the light of Sloan's ongoing survey initiatives.

Respondents were also surveyed to determine what they saw as barriers to their strategic use of online education and what role NASULGC might play in the incorporation of online learning into its member institutions' strategic planning.

Indeed, The NASULGC-Sloan National Commission on Online Learning's Survey of Presidents and Chancellors: Online Learning as a Strategic Asset represented one of the first large-scale polling of university and system CEO's on issues of online learning, based on responses from 77 college, university, and system heads.

\section{RESULTS OF QUANTITATIVE STUDY BY NASULGC}

Detailed results from this survey and the accompanying data analysis are available in NASULGC-Sloan National Commission (2007), but summary results clearly show that the data provided quantitative support to themes first isolated in the qualitative study. 
In the NASULGC-Sloan survey, institutional leaders confirmed a strong interest in the strategic importance of online learning with $66.7 \%$ of respondents noting that online education was critical to the long-term strategy of their institution, while only $4 \%$ responded that online learning played no strategic role. It was confirmed, however, this view has only developing reflection in formal, institutional planning procedures, as the survey data showed that online learning was present in the strategic plans of the polled institutions, although not yet in a majority of schools responding. Only $40.5 \%$ of respondents noted that online education was represented in the institution's strategic plan.

The NASULGC-Sloan data set also provided a more detailed look at operational areas of the modern university which school and system leaders saw as linked to online learning. In short, online or distributed education will profoundly influence individual sectors of an institution's operations such as admissions/recruiting, financial aid, and student services, potentially proving to be a strategic asset in a variety of ways for differing university audiences. Of particular interest to readers of this journal issue on the theme of access, responses indicated that, strategically, university leaders surveyed linked online learning primarily to issues of student access and recruitment:

- $\quad 71.4 \%$ of respondents linked online education to "increasing student access."

- $\quad 61.8 \%$ linked distributed education to "growing professional and continuing education."

- $\quad 57.1 \%$ looked to online learning to "attract students from outside the traditional service area."

Last, previous Sloan-supported nationwide surveys had identified a number of areas of concern for the growth of online course and degree offerings, including faculty acceptance of online education and the time and effort required to teach online. Survey designers wanted to verify whether institutional leaders shared these concerns.

The evidence from the resulting data set suggests that respondents did note the financial and time/effort costs of distributed learning, but do not strongly emphasize the lack of faculty acceptance:

- $\quad 40.8 \%$ of respondents noted that "online courses cost more to develop" than traditional offerings.

- $35.5 \%$ linked distributed education to "greater faculty time and effort” being required.

- Only $22.4 \%$ noted "a lack of acceptance” of online instruction by faculty.

\section{NASULGC-SLOAN NATIONAL COMMISSION ON ONLINE LEARNING BENCHMARKING STUDY}

National Commission plans for the immediate future include following the 2007 data collection with a planned "benchmarking study." The goal of this benchmarking activity is to begin the process of identifying some of the key factors that lead to "successful" online programs at public colleges and universities. To date, much of the research regarding online learning has focused on the questions of "what are campuses doing" and "why are they doing it." Not as much attention has been paid to the question of "how do campuses with successful online programs organize themselves" (revenue/business models, organizational structure, faculty incentives, etc.).

To begin to answer that question, the Commission will identify 18-24 joint NASULGC/AASCU members, equally divided between institutions identified by the Sloan-C survey as "fully engaged" and "engaged" (high potential for growth). Through a combination of well-defined short surveys and in-depth interviews, the Commission will build a profile of the attitudes and successful practices of the 
participating institutions in order to identify "best practices" that could be shared with/replicated by other campuses.

The study will provide an in-depth examination of the attitudes and beliefs of the senior academic leaders at these institutions, probing them for their goals and objectives. The in-depth interviews will also document the range of institutional approaches used by those who have been the most successful in introducing online course and programs to their institutions. Special attention will be paid to the barriers that had to be overcome and the strategies used. These responses can then be compared to those from institutions that are not as far along the path of online learning implementation, to see what lessons can be applied to their situation.

A second aspect of the study will be the first detailed cross-institutional examination of faculty attitudes and beliefs towards online learning. Faculty represent the second major constituency (after senior academic leaders) that are critical to the building a high-quality online learning program. Both national studies and single-institutional examinations have demonstrated that faculty attitudes are critical to the growth of any online learning program. There is, however, a large vacuum of reliable information on the exact nature of faculty attitudes and their influences.

\section{DISCUSSION AND CONCLUSIONS}

Online education is clearly growing as a major component within America's institutions of higher education. Through two linked studies — one qualitative, one quantitative-we have found that many of the Presidents or Chancellors are still in the process of discovering the potential of online learning as a strategic asset. Within the academic community, senior administrators and faculty have their own and varied views as to the potential of online learning as a means of educating students.

If online learning is to flourish and develop to its fullest potential, it might be helpful for the academic administrators and faculty to understand the views of the Presidents and Chancellors as in most institutions, they are the primary policy makers.

Over the last two years, the qualitative interviews of Presidents and Chancellors have demonstrated that, with some variation, they possess a reasonable knowledge of online learning and they look on it as a strategic asset, especially given the presence of a strategic problem or goal that online approaches might address. That being the case, interview discussions with presidents and chancellors often turned to the most efficient utilization of distributed education and its overall costs.

Following the qualitative interviews, NASULGC, in cooperation with the Alfred P. Sloan Foundation appointed a National Commission on Online Learning. The commission then conducted a quantitative, nationwide survey of presidents and chancellors, targeting the more than 200 NASULGC Institutions. Now, the data and insights gained from these two studies are being utilized to stimulate a national dialogue amongst university leaders to raise awareness of the potential of online learning as a strategic asset.

At present, the Commission has held or has planned over fifteen dialogue events, including many associated with significant national gatherings such as: NASULGC's Annual Meeting; NASULGC's Commission on Extension, Continuing Education and Public Service; National Association for Equal Opportunity in Higher Education Presidential Peer Seminar; NASULGC’s Council on Academic Affairs; 
and NASULGC's Council of 1890's Presidents and Chancellors, American-Indian Higher Education Consortium Annual Meeting and American Council on Education Annual Meeting.

These dialogue events typically involve a panel of presidents and other members of the NASULGC-Sloan Commission presenting the results of the qualitative and quantitative surveys as reported in their white paper. The meeting participants then discuss their views and experiences with online learning, best practices, barriers, and what information the commission might provide to assist them in using online learning as a strategic asset.

Of particular interest to the readers of this special issue will be the presidents' and chancellors' on-going, strong affirmation for the importance of online education as a means for "increasing student access," along with a significant desire to "attract students from outside the traditional service area." Such a view is not without policy implications. And although the term "access" was not defined in detail for the respondents, commentary provided in both the qualitative and quantitative studies show that university leaders are clearly moving beyond a mindset which links distributed education primarily to recruitment and financial gain, and more commonly viewing access in broader ways. This view of the present and future of online education clearly impacts discussions across the college or university on topics of financial aid, transfer credit acceptance, minorities, academic continuity, student services, and transnational education—and will engender policy development and debate for years to come.

\section{REFERENCES}

1. NASULGC-Sloan National Commission on Online Learning. Survey of Presidents and Chancellors: Online Learning as a Strategic Asset. Washington, DC: NASULGC, 2007.

2. Allen, I.E. \& J. Seaman. Growing by Degrees: Online Education in the United States, 2005. Needham, MA: Sloan Consortium, 2005.

3. Allen, I.E. \& J. Seaman. Making the Grade: Online Education in the United States, 2006. Needham, MA: Sloan Consortium, 2006.

4. Smith, S.H. \& S. H. Smith. "Positioning Online Learning as a Strategic Asset in the Thinking of University Presidents and Chancellors.” Paper presented to the 12th Sloan-C International Conference on Online Learning and to the 2006 NASULGC Annual Meeting, Houston, TX, 2006. 